\author{
Notas sobre a fotografia \\ analógica e digital
}

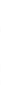

\author{
Antônio Fatorelli
}

Artigo recebido em: 05/05/2017

Artigo aprovado em: 05/06/2017 


\title{
Notas sobre a fotografia analógica e digital
}

\author{
Notes on analog and digital photography
}

\author{
Antônio Fatorelli*
}

Resumo: $O$ presente artigo destaca a dinâmica particular associada à dupla articulação da imagem fotográfica, simultaneamente referida a uma condição do mundo e ao seu próprio modo constitutivo. Evidencia-se, no atual momento transicional, marcado pela elasticização dos regimes temporais das imagens e pela sem precedente plasticidade do referente, a importância da reflexão crítica voltar-se à identificação das singularidades apresentadas pela produção fotográfica contemporânea, analógica e digital, nas suas recorrentes configurações híbridas e expandidas.

Palavras clave: Fotografia. Contemporâneo. Índice. Híbrido.

\begin{abstract}
The present paper highlights the particular dynamics associated to the double articulation of the photographic image, simultaneously referred to a condition of the world and its own constructive way. It is evident in the current transitional moment, marked by the elasticity of the temporary regime of images and by the unprecedented plasticity of the referent, the importance for the critical reflection to turn over to the identification of the singularities presented by the contemporary photographic production, analog and digital, in its recurring hybrid and expanded configurations.
\end{abstract}

Keywords: Photography. Contemporary. Index. Hybrid

* Universidade Federal do Rio de Janeiro. 


\section{Imagem e Presença}

As tecnologias da figuração automática, que contaram com a fotografia como o seu primeiro protótipo, materializaram a promessa de uma analogia mecânica entre imagem e mundo, uma analogia de natureza perceptiva, fundamentada do poder da imagem em reproduzir algumas das propriedades óticas recorrentes na visão ordinária dos corpos materiais. Pressupõe, nesse sentido, a existência de um estado anterior do mundo, sobre o qual a imagem vem se acrescentar na condição de imagem motivada, necessariamente dependente dos existenciais materiais prévios. Esse modo constitutivo pressupõe uma dimensão presencial, na qual encontram-se confrontados o mundo exterior, o fotógrafo e seus mediadores técnicos, e a imagem ela mesma.

Tal precedência do mundo material não inibiu o surgimento, no contexto da fotografia oitocentista e moderna, de imagens ficcionais mas indicam que, no caso das imagens fotocinematográficas, a ocorrência da instância ficcional delineia-se a partir do evento pró-fílmico ou pró-fotográfico ${ }^{1}$. Manifestamente, desde o seu advento, a fotografia retratou o universo ficcional, o imaginário do autor ou a dimensão invisível da realidade. Diferentes iniciativas e agendas apresentam essas orientações, do primeiro tableux, em que Hippolyte Bayard simulou a sua própria morte por afogamento, passando por uma genealogia que inclui a iconografia pictorialista nas suas inúmeras variações de forma e de estilo, a fotografia realista praticada por Oscar Rejlander e seus afiliados, as fotografias 'espirituais', que ofereciam prova irrefutável da existência de vida após a morte, todas amplamente disseminadas ao longo do século XIX.

Um amplo espectro de imagens que viria a ganhar ainda novos contornos no período posterior a Primeira Guerra Mundial, nas experimentações recorrentes nos trabalhos das vanguardas

1 Os eventos pró-fílmicos e pró-fotográficos compreendem o conjunto dos objetos dispostos diante da câmera no momento da filmagem ou da foto. 
históricas. Uma iconografia de tal forma diversificada que inclui, além desses movimentos deliberadamente concernentes às aproximações com outras formas de expressão e aos jogos de linguagem - como as montagens de inúmeros negativos e as experimentações com a temporalidade estendida, além da utilização de diferentes processos fotoquímicos, como a solarização e a cópia negativa -, o próprio movimento purista vanguardeado por Alfred Stieglitz, instituído sob o signo da noção de inefável, que encontrou nos ensaios de nuvens do próprio Stieglitz, orientado pelas correspondências entre as expressões subjetivas e as ocorrências materiais externas, e nas abstrações evocativas de Edward Weston, os seus primeiros contornos.

Tais tendências e movimentos marcantes na história da fotografia não abdicaram dos objetos e fenômenos do mundo, nem tampouco renunciaram às instâncias imediatas da experiência. Pelo contrário, extraíram das interações entre esses dois domínios o suplemento das suas imagens, os seus enigmas e as suas potências. Com efeito, a incidência de imagens ficcionais, fabulares ou visionárias manifesta-se sobejamente na história da fotografia, afirmando-se como o ponto de inflexão sobre o qual gravitaram inúmeros projetos visuais. No interior dessas poéticas marcadas pelas operações metafóricas e simbólicas, alusivas ou virtuais, a analogia visual produzida pela imagem fotográfica tem o sentido preciso de apontar para uma condição do mundo e, ao mesmo tempo, de marcar uma defasagem relativamente a qualquer instância anterior à imagem, em uma dinâmica particular, instituída pelas imagens fotomecânicas, que a diferenciam das tradicionais reivindicações miméticas endereçadas pelas formas visuais artesanais.

\section{A dupla articulação das imagens fotomecânicas}

Cabe indagar-se, no caso particular da representação fotográfica, sobre os laços de dependência entre imagem e mundo. 
Muitos fotógrafos criaram suas imagens no quarto escuro do laboratório fotográfico, explorando a natureza química do processo analógico, distantes das ruas e das relações mundanas. Foi o caso de Man Ray, László Moholy-Nagy e Christian Schad, que exploraram as possibilidades do fotograma ou ainda, mais recentemente, dos quimiogramas produzidos por Pierre Cordier, ou pelas séries Recriação e Derivação, realizadas por José Oiticica Filho, nos anos 1950. Contudo, apesar de significativas no âmbito da linguagem fotográfica, essas experiências não se confundem com a fotografia e, podemos avaliar, o nosso investimento habitual na imagem fotoquímica seria de natureza bem diversa se conhecêssemos apenas esse repertório de imagens criadas exclusivamente a partir de procedimentos químicos laboratoriais.

Convémigualmente, e de modo complementar, circunscrever a maneira pela qual as imagens fotográficas são normalmente submetidas aos procedimentos de manipulação analógicos. Motivação especialmente relevante, uma vez considerado o papel crucial desempenhado pela analogia visual no modo singular de sedução e de engajamento produzido pela fotografia. Precisamente, a circunstância de apontar para uma condição do mundo, segundo os critérios de analogia perceptiva e, igualmente marcante, em concordância aos princípios do traço, da marca e do vestígio. Não obstante, ao invés de apresentar-se como cópia ou duplicata, a imagem fotográfica exibe uma defasagem relativamente às instâncias anteriores. Num certo sentido, ela institui-se segundo seus procedimentos técnicos, afirmando sua independência relativamente a qualquer condição precedente ou exterior à sua criação e, nesse particular, pode-se conceber que a imagem se configura em concordância aos seus determinantes tecnológicos e processuais, de modo a instaurar a sua própria realidade.

$\mathrm{O}$ foco nessa dupla articulação da imagem - nomeadamente, nas relações concomitantes de proximidade e de afastamento da imagem relativamente ao referente externo - aponta para a existência de um conjunto de singularidades concernentes à fotografia, com a 
prerrogativa de desviar-se das proposições ontológicas, ancoradas em um projeto estético reducionista, voltado à observância de orientações formais específicas, como verificado no caso da agenda modernista pura e direta.

De modo bem diverso, a investigação orientada pelas relações diferenciais estabelecidas pela dinâmica da dupla articulação acolhe as configurações híbridas ${ }^{2}$ e os múltiplos formatos, além de revelar a intenção de entrever um horizonte de possíveis, inclusive de conceber o advento de modos fotográficos ainda desconhecidos. No contexto das suposições que acompanham a prática e o pensamento sobre a fotografia, a defesa desse território permanentemente negociado, implica na refutação da concepção sobejamente parcial, de que a imagem fotográfica se apresenta exclusivamente associada ao referente, de tal modo a poder prescindir das mediações próprias às linguagens formais ou, no outro extremo, da crença de que a imagem fotomecânica se encontra liberta das constrições presentes no mundo físico imediato.

Manifestamente, a imagem fotográfica integra o mundo material e, em algumas circunstâncias, produz a sua própria realidade, unicamente em consideração aos seus procedimentos técnicos e processuais. Como nos casos de certas fotografias de Jacques Henri Lartigue, em que a velocidade do obturador registrou uma cena imperceptível ao olho. Ou, ainda, nos casos em que o motivo ou o tema da foto remete a outras imagens, numa referência em abismo ao modo singular da fotografia representar certos eventos. Nesse último caso, um procedimento indicativo de que o

2 Empregamos a noção de "híbrido" na acepção de Latour (LATOUR, 1994, p. 16), ao designar os mistos de natureza e cultura, em oposição às práticas de purificação. Entretanto, de modo mais aproximado às análises teóricas em torno da fotografia, usaremos igualmente os termos "fotografia expandida" e "fotografia contaminada", como endereçadas por Entler, ao referir-se ao contexto posterior ao debate ontológico, corrente nos anos 1980: "De outro lado, enquanto ainda nos perguntávamos sobre o que distingue a fotografia de outras imagens, os artistas passaram a ignorar essas fronteiras e a experimentar todo tipo de interação. Para dar conta disso, passamos a falar numa imagem híbrida, numa fotografia contaminada, numa fotografia expandida..." (ENTLER, 2011). E, também, em referência à tese de Rubens Fernandes Júnior (2002), intitulada "Fotografia expandida". 
próprio repertório das imagens fotográficas se institui, por vezes, como referência originária, deflagrador dos processos de criação de novas imagens, ao modo de um dispositivo metalinguístico.

Afigura-se, nesses casos - como em muitos outros, como veremos a seguir -, a proeminência da função apresentativa das imagens, concomitante à crescente complexidade do mundo material e do universo imagético. Práticas como a apropriação de imagens já existentes no âmbito da mídia e dos arquivos públicos, situação em que o fotógrafo propriamente não fotografa; de elaboração de cenários criados para serem fotografados, sem qualquer precedente na realidade prévia; de empréstimos de procedimentos originados em outros domínios - como o cinema, o teatro, a literatura e a performance -, em todas essas situações, o que apresenta-se recorrente é a intercessão de novos mediadores, e a proliferação de instâncias materiais e imateriais nas etapas de pré-produção, produção e pós-produção da imagem.

\section{Expansões}

Presenciamos, no cenário contemporâneo, uma significativa expansão da fotografia, ora tencionando os protocolos tradicionalmente vinculados ao meio, outras vezes esgarçando as fronteiras do campo. Essas práticas pós-modernas ou contemporâneas, reunidas sob a rubrica de fotografia expandida, endereçam outras poéticas e reiterados distanciamentos, com a potência de subverter, cada uma a seu modo, os balizadores formais e conceituais da fotografia moderna convencional.

Considerando que, no contexto das formações modernas, foi possível conceber o estabelecimento de relações suficientemente estáveis entre a imagem, o referente e o fotógrafo, definidas em concordância aos princípios de autonomia de cada um desses termos, cabe observar, no contexto contemporâneo, a ocorrência de relações significativamente alteradas em vista da crescente 
plasticidade dos corpos materiais e da exponencial flexibilidade da imagem, além de entrever o redimensionamento dos papéis historicamente atribuídos ao fotógrafo.

Ao considerar os desdobramentos da revolução tecnocientífica proporcionadas pelas Ciências da Complexidade, Luiz Alberto Oliveira (2006, p. 48) observa o surgimento de três novas figuras de unidade constitutiva elementar: os 'átomos de matéria' (as partículas elementares), de atividade (os quanta de ação), e de organização (os bits), prenunciando que,

pode-se dizer que, hoje, estamos nos distanciando desta concepção platônica de simulacro. Devido às inovações revolucionárias que surgiram ao longo do século XX, estamos nos tornando capazes de intervir nos próprios fundamentos, nos modos básicos de estruturação, dos corpos materiais. Ao mesmo tempo, os corpos materiais, enquanto fonte de estímulos para nossa percepção, estão se tornando plásticos (OLIVEIRA, 2006, p. 46).

Oliveira (2006, p. 47) aponta, portanto, para as transformações verificadas no âmbito da maior manuseabilidade dos corpos matérias e, também, da crescente flexibilização dos regimes de percepção, motivada pela "capacidade de engendrar fluxos de sinais que são indistinguíveis dos emitidos pelos referentes tradicionais".

Por sua vez, acompanhamos no âmbito dos usos e formatos recentes da fotografia, a crescente migração, das imagens produzidas no dia a dia, dos álbuns de família para as redes de compartilhamento, como Flicker, Youtube e Facebook, ocasionando uma extraordinária modificação nos hábitos e nos papéis consignados à fotografia. Anteriormente referida a função memorialística, a imagem fotográfica passa agora a desempenhar funções crescentemente associadas à experiência atual, afigurando-se preferencialmente como instância potencializadora dos afetos compartilhados nos 
afazeres da vida cotidiana. Desloca-se, deste modo, do formato fechado, por definição imutável, dos antigos álbuns, para a forma fluida dos instantâneos registrados em tempo real, periodicamente substituídos nos feeds dos sites de compartilhamento. Na outra ponta desse território, no contexto das exposições fotográficas, acompanhamos a crescente proliferação de trabalhos que migram da foto objeto, fixa e bidimensional, para a foto projeção, em que a imagem exibe uma condição especialmente modular, podendo ser sobreposta a outras mídias, como o vídeo e os formatos digitais, de modo a comportar múltiplas dimensões e temporalidades.

Destacam-se, nesse domínio da fotografia profissional, endereçada à galerias e museus, três tendências recentes, exemplarmente inscritas no atual contexto de elasticização dos regimes imagéticos. Inicialmente, os trabalhos desenvolvidos por um grupo de artistas norte-americanos - Sherrie Levine, Richard Prince e Barbara Kruger, entre outros -, precursores do pósmodernismo, que estabeleceram, no final dos anos 1970, uma poética fortemente marcada pela postura crítica frente a indústria cultural e a sociedade do espetáculo, com ênfase no questionamento sobre as instâncias sociais de poder, as questões de gênero e o papel das imagens tecnológicas, em especial da imagem fotográfica impressa de grande circulação, na conformação do imaginário social.

Esta prática de apropriação de imagens originadas no circuito da mídia e dos arquivos iconográficos os mais variados proporciona uma exponencial intensificação das propriedades reprodutivas da fotografia, nesse momento ela mesma tornada paradigmática no âmbito da configuração do consciente coletivo e como elemento simbólico mediador das relações sociais. A autoria, uma problemática central na prática apropriacionista, adquire contornos excepcionais no contexto dessa estratégia, uma vez que o fotógrafo não fotografa, desviando-se das atribuições técnicas e autorais que tradicionalmente assinalaram a presença do criador no processo de elaboração da imagem. Mas, de modo igualmente desterritorializado, também a presença do fotógrafo no local da 
tomada e a própria imediaticidade do referente encontram-se canceladas, agora referidas a uma autoria coletiva e a um significado fixado em rede.

Os surpreendentes tableaux de Oliver Boberg, integram uma outra tendência no âmbito da elasticização dos regimes imagéticos contemporâneos. Apresentando situações do dia a dia, como um parque de estacionamento, um prédio em construção ou um arbusto, supostamente reais mas efetivamente maquetes meticulosamente concebidas em estúdio, a criação dessas imagens demandam um intenso trabalho artesanal e inúmeras etapas de pré e de pós-produção. Uma condição recorrente nos trabalhos de inúmeros outros influentes fotógrafos contemporâneos, entre eles Sandy Skoglunt, James Casebere e Thomas Demand. O real, o referente, a coisa em si ou o mundo objetivo - esses inúmeros modos recorrentes de nomear a realidade precedente a partir da qual a imagem se constituiria na condição de representação motivada - apresentam-se cancelados, substituídos pela imediaticidade da imagem fotográfica, investida do status de instância inaugural, ponto de origem irradiador dos seus endereçamentos simbólicos.

A terceira tendência apresenta uma condição temporal singularmente complexa, múltipla e diversa. Abrange as animações da série Fotografias que respiram, de Gustavo Pellizzon; as fotografias cinéticas da série Noir, a noite na metrópole, de Antonio Saggese, os trabalhos intitulados Frutos estranhos, de Rosangela Rennó e a instalação Ruurlo, Bocurloscheweg, de David Claerbout, entre outras inúmeras obras recentes, marcadas pelo propósito de conferir movimento, efetivo ou pressuposto, às imagens estáticas. Situadas na fronteira com a imagem em movimento do cinema, do vídeo e das novas mídias, essas obras realizam o anseio, presente de diferentes maneiras na história do meio - no borrado, nos efeitos da inscrição do movimento nas tomadas de longa exposição, como também nos diferentes modos de serialização e de montagem -, de trabalhar os paradoxos da imagem dita instantânea, o seu movimento potencial, o seu quase desdobramento no tempo. Esses múltiplos e 
variados formatos facultados pela imagem projeção, potencializam as interseções entre diferentes mídias, em especial com as imagens em movimento do cinema e do vídeo, expandindo as áreas de sobreposições e os domínios de influências recíprocas, no âmbito da intermidialidade, em total desacordo com as demandas puristas de autonomia e de autossuficiência do meio.

Apesar de diferenciarem-se substancialmente, essas poéticas contemporâneas investem nos pontos cegos do pensamento modernista hegemônico, hostil a todas as iniciativas situadas fora do âmbito da imagem única e instantânea, desestabilizando as suas convenções estéticas, temporais e performativas, de modo a comprometer definitivamente os princípios balizadores da demanda ontológica. Além de endereçarem, cada uma a seu modo, um convite à percepção, no momento atual, da complexidade das imagens, do papel progressivamente substancial desempenhado pelos mediadores tecnológicos e, igualmente notável, da crescente estratificação e manuseabilidade do mundo material ele mesmo.

De modo menos referenciado na agenda moderna - afinal, inúmeros movimentos fotográficos desenvolveram-se à margem das proposições puristas - devemos reconhecer a presença de múltiplos formatos desde os seus primórdios - e sublinhar que essas três vertentes da fotografia expressam a complexidade do próprio meio. Nosso desafio encontra-se exatamente nessa dupla articulação: no propósito de apontar para a multiplicidade da fotografia tradicional, de base fotoquímica, e ao mesmo tempo de desviar-se das proposições eufóricas relacionadas às tecnologias digitais, que atribuem o potencial criativo e disruptivo da fotografia unicamente às singularidades da codificação numérica.

\section{Contágios e sobreposições}

Pretende-se destacar as ocorrências de estéticas pluralistas no curso da própria história do meio, de modo a evidenciar a natureza reducionista da agenda purista e as limitações das 
formulações ontológicas. E, simultaneamente, refutar os discursos utópicos que atribuem à base técnica digital o mérito de superar as limitações atribuídas ao analógico, num suposto movimento de ultrapassagem e de libertação que, avaliado à distância, demonstrase mais referido às restrições do formato purista do que ao universo das imagens fotográficas e aos diferentes movimentos estéticos historicamente manifestos.

Se a formulação ontológica se voltou enfaticamente à celebração do puro e do idêntico, a crítica da fotografia contemporânea deve legitimar as formações híbridas e compostas, as passagens e os atravessamentos entre os meios. Portanto, de reconhecer e de promulgar as estratégias decorrentes: 1. da presença de uma realidade crescentemente estratificada; 2 . da proliferação da produção de imagens a partir de outras imagens; 3 . da constituição de situações reais criadas para a câmera; 4. das sobreposições entre a fotografia, o cinema, o vídeo e as novas mídias e; 5. da condição inaugural e projetiva das imagens.

A noção de "o fotográfico" empregada por Bellour e Dubois em uma conjuntura marcada pelos atravessamentos entre as linguagens e pelas experimentações com diferentes suportes, indica um estado permeável da fotografia, uma vez dissociada das intenções identitárias recorrentes nas teses essencialistas voltadas à defesa das fronteiras, do território próprio e dos procedimentos específicos. Na acepção de Bellour,

o "fotográfico" não é uma categoria exclusiva à fotografia, nem aos seus procedimentos específicos, ou seja, o "fotográfico" é uma condição transversal a vários gêneros e práticas da imagem (...) e liga-se sobretudo a um campo de visualidade do qual sobressaem as ações de paragem e desdobramento do movimento, bem como os efeitos que essas experiências induzem na percepção de um tempo (complexo, aberto, "cristal") que é imanente à imagem (apud MACHADO, 2008, p. 70). 
Diante da variabilidade das formas instalativas e dos diferentes dispositivos recorrentes nas exposições contemporâneas, como exibidos nas obras de David Claerbout, Wyn Geleynse, Egbert Mittelstadt e Rosangela Rennó, entre outros, Philippe Dubois (2009) observa que,

é preciso, todavia, repensar a categoria de "fotográfico" como algo intensivo, que excede o domínio das fotosobjetos e das obras-imagens para se engajar no caminho dos processos e das modalidades. Nesse sentido, o "fotográfico" (tão distinto da fotografia quanto o "videográfico do vídeo) é a essência da variabilidade da imagem-foto, sua potência de transformação, sua mutabilidade intrínseca aos processos tecnológicos cruzados das formas e dos dispositivos contemporâneos (DUBOIS, 2009, p. 89).

Anteriormente mobilizado com o propósito de circunscrever as singularidades processuais do meio, a recuperação do conceito de "fotográfico" por Bellour e Dubois, agora significativamente ampliado de modo a abranger as regiões de intercessão da fotografia com outras formas de expressão, proporciona a oportunidade de desviar-se de uma filosofia do mesmo, da origem, do puro e da imitação para situar-se no território sempre negociado do múltiplo, das interfaces, das complexidades, dos paradoxos e das diferenças presentes desde sempre na história da fotografia, ainda mais intensificado - ou melhor, problematizado -, no atual momento de trânsito generalizado dos signos. $\mathrm{O}$ tempo ${ }^{3}$, mais do que a expressão espacial do diagrama delimitador dos contornos dos territórios consignados a cada meio, apresenta-se como o vetor fundamental nesse contexto de redimensionamento conceitual.

Com efeito, a operação através da qual a imagem fotográfica deixa entrever sua temporalidade complexa já estava

3 Desenvolvemos extensamente essa abordagem no livro "Fotografia contemporânea: entre o cinema o vídeo e as novas mídias” (FATORELLI, 2013). 
presente nas primeiras tentativas de fixação da imagem no período que se seguiu ao seu advento, na fotografia pictorialista oitocentista, na cronofotografia de Jules Etienne-Marey e Edward Muybridge, nas diferentes experimentações das vanguardas dadaísta, futurista e surrealista, nos ready-mades e nas obras de inspiração cronofotográfica de Marcel Duchamp, nas estratégias de serialização utilizadas por Andy Warhol e em outros inúmeros trabalhos que integram esse vasto repertório das modalidades de inscrição temporal nas imagens estáticas.

É essa operação fundamental sobre o tempo, de desdobramento e de multiplicação de vetores, presentes no contexto das imagens analógicas, disseminada nas produções fotográficas pós-modernas e recorrentes na morfogênese da imagem digital, que estabelece um curto-circuito no cerne da suposição ontológica que avaliza as premissas associadas ao ideal de representação pura e direta, supostamente sancionada pela gênese automática do processo. Associada ao tempo complexo, a imagem fixa exibe seu status múltiplo, além de estabelecer uma relação problemática com o tempo presente e com o referente imediato.

\section{A dupla articulação da fotografia digital}

Passado o período inicial de emergência da cultura digital, marcado pelas iniciativas no âmbito da computação gráfica voltadas à criação de mundos artificiais, observamos a expressiva presença de trabalhos produzidos sob o signo da negociação entre os modos de inscrição dos códigos analógico e digital. Rosen (2001) pontua que esse momento de negociação coincide com a incorporação, pelo digital, das convenções associadas à codificação perspectiva, caracterizadas pela produção dos efeitos de semelhança. Uma operação, portanto, subtrativa do ponto de vista da utopia digital, uma vez que ao assimilar o modelo da perspectiva e os códigos miméticos, as demandas de irrestrita liberdade endereçadas pela 
retórica da ruptura encontram-se severamente comprometidas.

Com efeito, ao simular o dispositivo analógico de registro, a câmera digital passa a incorporar as singularidades da codificação perspectiva e os princípios, materiais e imateriais, tradicionalmente vinculados à cultura visual analógica. Uma decorrência decisiva desse processo de emulação refere-se à particularidade de que, ao perpetuar a dependência aos sinais de luz no momento do registro da imagem, realizada na presença do mundo físico, a fotografia digital incorpora as fabulações relacionadas ao modo de inscrição indicial. Nesse contexto de remediação da fotografia analógica pela fotografia digital, a operação fundamental realiza-se, portanto, no âmbito do registro da imagem, tornando secundária a circunstância dela ser gravada em um sensor eletrônico, e não mais em um suporte fotoquímico, tanto quanto às condições posteriores decorrentes do seu modo de circulação.

Não se pretende, no curso dessa proposição, menosprezar as recentes e cada vez mais acessíveis possibilidades de manipulação das imagens proporcionadas pela codificação digital, nem tampouco minimizar as inúmeras possibilidades instauradas pelo compartilhamento de imagens em tempo real mas, sublinhar que, do mesmo modo que as imagens de fatura analógica, também as fotografias digitais encontram-se contaminadas, para usar uma figura cara ao modo de impressão indicial e, nesse sentido, balizadas pela lógica do traço, inscrevendo-se, igualmente, no contexto dos argumentos autenticadores da dupla articulação da imagem - nomeadamente, das relações simultâneas de proximidade e de afastamento relativamente ao referente externo - anteriormente anotados em consideração à fotografia tradicional. De conceber, portanto, que também a imagem digital não prescinde do aqui e agora, da fisicalidade do mundo e dos objetos materiais, ao tempo que se configura em concordância aos seus determinantes processuais e instaura a sua própria realidade.

Compartilhamos a premissa de Gunning (2016) ao pontuar que a intervenção digital não se volta prioritariamente à criação 
de uma nova imagem - como experimentado nos primórdios da infografia - mas à manipulação/transformação de uma imagem preexistente, configurada pelo princípio da projeção, em concordância às prerrogativas indiciais e, do mesmo modo, a análise desenvolvida por Rosen, no sentido de demonstrar que o digital encontra-se referido à complexidade do real, dependente do contato físico entre signo e objeto, em conformidade aos princípios da inscrição indicial, do mesmo modo que o analógico (ROSEN, 2001). Tomadas em consideração à dupla articulação da imagem, essas observações de Gunning e de Rosen proporcionam um contexto epistemológico apropriado ao entendimento crítico da cena contemporânea. Entretanto, não está em causa, definitivamente, a retomada dos antigos discursos de viés ontológico predominantes no período dos anos 1980, como observou Entler (2011), defensores da preeminência da função icônica, indicial ou simbólica do signo. Muito menos a reabilitação do pressuposto princípio de realidade, frequentemente relacionado ao realismo fotográfico.

De outro modo, nesse momento transicional singularizado por uma sem precedente plasticidade do referente, pela exponencial flexibilidade dos regimes imagéticos e pelas novas e desafiadoras atribuições designadas ao fotógrafo, o foco do olhar reflexivo deve recair sobre enormes poderes das imagens, recorrentes nos seus múltiplos formatos.

\section{Referências}

DUBOIS, Philippe. Sobre o 'efeito cinema' nas instalações contemporâneas de fotografia e vídeo. In: MACIEL, Katia (Org.). Transcinemas. Rio de Janeiro: Contra Capa, 2009.

ENTLER, Ronaldo. Ser ou não ser fotografia? O percurso das teorias ontológicas. Icônica, São Paulo, 23 maio 2011. Disponível em: <http://www.iconica.com.br/site/ser-ou-nao-ser-fotografia-o- 
percurso-das-teorias-ontologicas $>$. Acesso em: 7 abr. 2017.

FATORELLI, Antonio. Fotografia contemporânea: entre o cinema, o vídeo e as novas mídias. Rio de Janeiro: Senac, 2013.

FERNANDES JÚNIOR, Rubens. Fotografia expandida. 2002. Tese (Doutorado em Comunicação e Semiótica) - Pontifícia Universidade Católica de São Paulo, São Paulo.

GUNNING, Tom. Qual a intenção de um índice? Ou, Falsificando fotografias. In: FATORELLI, Antonio; CARVALHO, Victa;

PIMENTEL, Leandro (Org.). Fotografia contemporânea: desafios e tendências. Rio de Janeiro: Mauad, 2016.

LATOUR, Bruno. Jamais fomos modernos. Rio de Janeiro: Editora 34, 1994.

MACHADO, Arlindo. O cinema e a condição pós-midiática. In: MACIEL, Katia (Org.). Cinema Sim: narrativas e projeções. São Paulo: Itaú Cultural, 2008.

OLIVEIRA, Luis Alberto. Homo lumines. In: FATORELLI, Antonio; BRUNO Fernanda (Org.). Limiares da imagem. Rio de Janeiro: Mauad Editora, 2006.

ROSEN, Philip. Change mummified: cinema, historicity, theory. Minnesota: University of Minnesota Press, 2001. 